\title{
EFFECT OF REPEATED INTRAVENOUS ADMINISTRATION OF XYLAZINE ON SEDATION, ANALGESIA AND ECG PARAMETERS IN DONKEYS (EQUUS ASINUS)
}

\author{
NAGLAA A. GOMAA*; ALAA E. GHAZY** and AYMAN S. ATIBA*** \\ * Lecturer of animal medicine, Department of Animal Medicine, Faculty of Veterinary Medicine, Kafrelsheikh University, \\ Kafrelsheikh, 33516, Egypt, Tel/Fax, +20473231311. \\ ${ }^{* *}$ Lecturer of veterinary surgery, anesthesiology and radiology, Department of Surgery, Anesthesiology and Radiology, \\ Faculty of Veterinary Medicine, Kafrelsheikh University, Kafrelsheikh, 33516, Egypt, Tel/Fax, +20473231311. \\ **** Lecturer of veterinary surgery, anesthesiology and radiology, Department of Surgery, Anesthesiology and Radiology, \\ Faculty of Veterinary Medicine, Kafrelsheikh University, Kafrelsheikh, 33516, Egypt, Tel/Fax, +20473231311.
}

Email: naglaagomaa505@yahoo.com

Assiut University web-site: www.aun.edu.eg

\section{ABSTRACT}

Received at:10/9/2015 Xylazine Hcl was generally used in veterinary medicine for its sedative and moderate analgesic effect. This experimental study was undertaken to determine the effect of repeated intravenous (IV) administration of xylazine on sedation and analgesia as well

Accepted: 11/10/2015 as cardiac arrhythmia using ECG in donkeys. Three repeated injections of xylazine $(0.5 \mathrm{mg} / \mathrm{kg})$ with 10 minute interval were injected IV in six healthy adult donkeys. Sedation score, analgesic score, heart rate (HR), respiratory rate, rectal temperature and ECG parameters were recorded before and after 2, 5 and 10 minutes from injection for each injection and then at 5 minutes intervals until complete recovery from sedation and the normal ECG was recorded. Deep sedation was obtained 5 minutes after the second injection in all donkeys, and the length of sedation lasted $71 \pm$ 6 minutes. The deep analgesia was obtained 5 minutes after the third injection in all donkeys, and the length of analgesia lasted $62 \pm 5$ minutes. There was a highly significant decrease in HR after the third injection $(P<0.01)$. Normal HR was obtained in all donkeys after $75 \pm 10$ minutes of the third injection. Cardiac arrhythmia as atrial fibrillation and AV block were recorded after second and third injection but this arrhythmia was transient. We can conclude that repeated injection of xylazine Hcl give acceptable results either for sedation or ECG parameters in donkeys.

Keywords: Analgesia, Donkey, ECG, Sedation, Xylazine.

\section{INTRODUCTION}

Xylazine $\mathrm{HCl}$ (Alpha 2-adrenoceptor agonist) is generally used in veterinary medicine for its sedative and moderate analgesic effects. It is one of the common tranquilizers which used in veterinary field for minor procedures (Thurmon and Benson, 1996). Although its wide use, xylazine give only a short period of action of approximately 20 to 30 minutes, which impedes its use when prolonged analgesia is necessary (Daunt and Steffey, 2002). Repeated injections of Xylazine are mandatory in long standing surgery in equine (Hewes et al., 2007). Under field conditions, the most commonly surgical procedures in donkeys were performed in standing position without general anaesthesia if adequate analgesia and sedation are provided (Joubert et al., 1999). To achieve an adequate preoperative analgesia in donkeys, higher dosages or shorter dosing intervals may be required since they metabolize many drugs more rapidly than horses (Klide et al., 1975). At a single recommended dose rate, Xylazine has variable and considerable secondary effects on cardiovascular system especially cardiac arrhythmia in horses (Muir and Hamlin 1975; Kirkpatrick, 1978; Kolata and Rawlings, 1982; Hikasa, 1992). Therefore, repeated administration of xylazine may extend the analgesic effect but it could produce a further critical effect on cardiac arrythemia.

The electrocardiogram (ECG) is the most accurate method for documenting cardiac arrythemia and conduction abnormalities (Fregin, 1985). Numerous studies have been carried out on electrocardiography in horses, however limited information exists regarding to electrocardiography in donkeys. This study was carried out to determine the effect of repeated intravenous administration of xyalzine $\mathrm{HCl}$ on sedation, analgesia and the electrocardiographic parameters in donkeys. 


\section{MATERIALS and METHODS}

\section{Animals}

The study was conducted on 6 apparantly healthy donkeys (Equus asinus) ( 2 females and 4 males), their body weight ranged from 150-200 kg and aged 2-7 years. All donkeys were considered to be healthy by clinical, laboratory and ECG examinations. The donkeys included in this study were free from any cardiac diseases. Food, but not water, was withheld six hours before procedures. The Animal Welfare and Ethics Committee of Kafrelsheikh University approved the experimental protocol.

\section{Study design}

The study was carried out as an experimental trial. Three repeated original dose of xylazine were administered IV to all examined donkeys with 10 minutes intervals. The dose of xylazine (Xyla-Ject, ADWIA Pharmaceuticals Co. Cairo, Egypt) was chosen according to a recommended manufactured dose in equine $(0.5 \mathrm{mg} \mathrm{kg}-1)$. Three repeated doses of xylazine were administered intravenous with 10 minutes interval.

\section{Assessment of sedation and analgesia}

Sedation was characterized by lowering of the head, relaxation of the upper eyelids, drooping of the lower lip and dropping of the ears. The sedation was graded according to a numerical scale 0-3 (Table 1) (Taylor et al., 1988). The onset of sedation was recorded. The degree of analgesia was assessed by the response of the animal to a needle prick applied to the base of the ear, shoulder, flank area and perineum at time 0 (baseline value), 5, 10, 15, $20 \mathrm{~min}$ and every $5 \mathrm{~min}$ thereafter until the end of the procedure. The analgesia was scored according to a numerical rating scale 0-3 (Table 1) (Taylor et al., 1988).

\section{ECG}

The electrocardiographic traces were obtained using (Cardio Max FX-7102, Fukud denshi co; Japan) adjusted to paper speed at $50 \mathrm{~mm} / \mathrm{sec}$ and sensitivity at $10 \mathrm{~mm} / \mathrm{mV}$. The modified ambulatory standard base-apex lead for large animals was applied according to Young, 2004. Briefly, the clips of electrodes were fixed on the skin after shaving the hair and application of electrodes past or acoustic gel. In the base-apex lead, the (black) electrode serves as a reference electrode for ECG and it was placed in the right side in front of the scapula, while the positive (green) electrode was placed on the left 5th intercostal space over the apex beat area of the heart, caudal to left elbow, at the level of olecranon process while the negative (red) one was placed on the right side of thorax at 3 th intercostal space over the base of the heart behind the right elbow. The remaining electrode (white) can be positioned anywhere on the back of the donkey. All records were taken while the donkeys were standing in the stock; the fore limbs were kept parallel to each other and perpendicular to the long axis of the body. The normal ECG was recorded while the donkey was calm and the optimal ECG tracing was obtained. Qualitative and quantitative assessments of ECG tracings were done. The morphology of $\mathrm{P}, \mathrm{T}$ waves and QRS complexes and duration of different complexes and the interval were assessed.

Normal ECG tracings, sedation score (SS), analgesic score (AS), heart rate (HR), respiratory rate and rectal temperature (RT) were recorded before xylazine administration and after 2, 5 and 10 minutes of administration. After 10 minutes of last third injection, all assessments were recorded every 5 minutes till the normal ECG was recorded.

\section{Data analysis}

Data was analyzed using a statistical software package (SPSS for Windows, Version 16. Chicago, SPSS Inc.). All the data are presented as means \pm standard deviations (SD). Repeated measure ANOVA was used for comparison of measured parameters before and after repeated drug injections. Significant differences were considered at $(p<0.05)$.

\section{RESULTS}

Moderate sedation was obtained after 10 minutes of the first injection of xylazine with (sedation score 2). Although, deep sedation (sedation score 3) was obtained after 5 minutes of the second injection. The average length of sedation was $71 \pm 6$ minutes from the first injection till complete recovery from sedation. No donkey became recumbent. On the other hand, moderate analgesia (analgesic score $\geq 2$ ) was obtained 5 minutes after the third injection of xylazine in all donkeys. The average length of analgesia was $62 \pm 5$ minutes from the begaining of administration till complete recovery.

There was a significant decrease in HR after 2 minutes from the first injection of xylazine. There was a highly significant decrease in HR after the third injection if compared with the normal value (Table 2). In all examined donkeys, HR returned to normal after $75 \pm 10$ minutes. No abnormal heart sounds were detectable by auscultation of the heart in examined donkeys.

Electrocardiographic parameters obtained from the base-apex lead of examined donkey before and after administration of three successive doses of xylazine were recorded (Tables 3\&4), (Fig.1. A, B, C, D, E, and F). In ECG tracing, the normal morphology of $P$ wave was a simple, monophasic, positive defalcation in all examined donkeys (Fig. 1. A). No significant differences in $\mathrm{P}$ wave duration and amplitude after xylazine injections except 5 minutes after the third dose in 2 donkeys, $\mathrm{P}$ wave could not be identified because of atrial fibrillation (Fig.1. E). In addition a significant increase in PR duration was recorded 5 
minutes after second and third dose injection. There were no significant differences in QRS duration after xylazine injections at all examined times. However, there was a significant increase in ST and QT durations after second and third dose of xylazine injections (Table 3). $\mathrm{T}$ duration increased significantly after xylazine injections and its amplitude increase significantly after 2 minutes of third dose. Besides, there were several morphological changes in $\mathrm{T}$ wave configurations. Before injection, $\mathrm{T}$ wave was negative deflection and became biphasic (+/-) deflection 10 minutes after the first injection, and 2 and 5 minutes after the third injection (Fig.1. C, E, F). There were no significant changes in $\mathrm{Q}$ and $\mathrm{S}$ amplitude after xylazine injections.

Several changes in QRS complex configurations were observed after xylazine injection. QRS was biphasic (+/-) deflections 5 minutes after the third injection. In addition, there was a significant decrease in $\mathrm{R}$ amplitude after 5 minutes of second injection and after 2 and 10 minutes of the third injection of xylazine (Table 4).

\section{Figure legends}

Figure 1, (A): Normal ECG of donkey before injection of xylazine showing normal rhythm and normal PQRST. (B): ECG after 2 minutes of first dose of xylazine showing decreased HR (sinus bradycardia), decreased R amplitude and increased $\mathrm{T}$ wave duration and amplitude. (C): ECG after 10 minutes of first dose of xylazine showing normal HR, decreased $\mathrm{P}$ amplitude, inconstant $\mathrm{R}$ duration and biphasic $\mathrm{T}$ wave. (D): ECG after 2 minutes of the second dose of xylazine showing sinus bradycardia. (E): ECG after 2 minutes of third dose of xylazine showing atrial fibrillation decreased R-amplitude and biphasic T wave. (F): ECG of donkey after 5 minutes of third dose of xylazine showing sinus bradycardia, atrial fibrillation, and biphasic $\mathrm{T}$ wave.

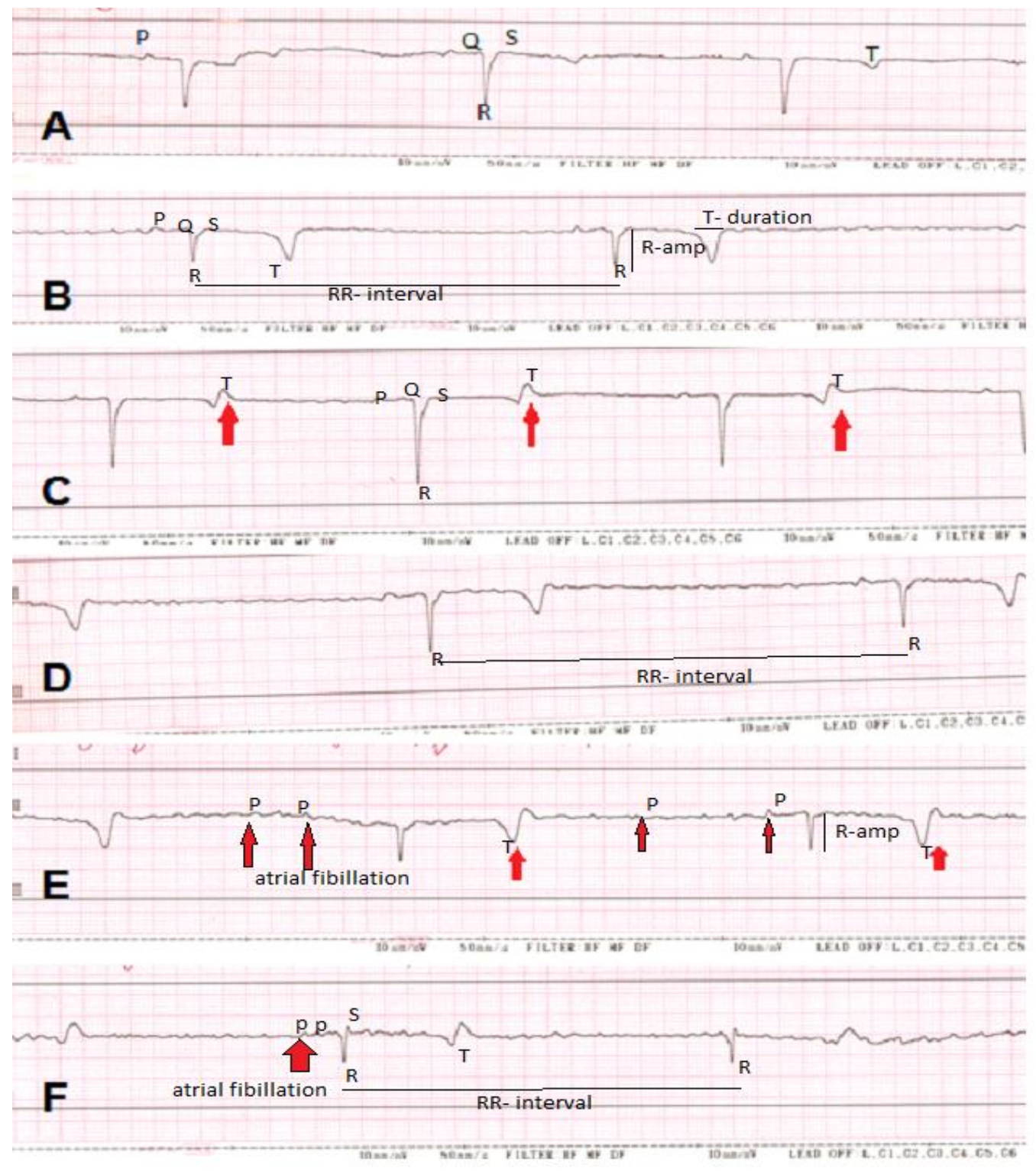


Table 1: The sedation and analgesic scores according to (Taylor et al., 1988).

\begin{tabular}{cll}
\hline Category & Sedation scores & Analgesic Scores \\
\hline Normal (0) & No sedation & No analgesia \\
\hline Mild (1) & $\begin{array}{l}\text { Head normal position, relaxed lower lip and } \\
\text { eyelids }\end{array}$ & Conscious awareness and subdued response \\
\hline Moderate (2) & Head lowered, drooping eyelids and lower lips & Awareness but no response \\
\hline Deep (3) & $\begin{array}{l}\text { Head fully lowered, drooping of the ears, } \\
\text { eyelids }\end{array}$ & No response to test \\
\hline
\end{tabular}

Table 2: Mean \pm SD of HR (bpm) in experimental donkeys before injection (Baseline) and after repeated 3 injections of xylazine.

\begin{tabular}{lccccc}
\hline \multicolumn{2}{c}{ Parameters } & Baseline & X-1 & X-2 & X-3 \\
\hline \multirow{2}{*}{ HR } & & $52.67 \pm 1.69$ & & & \\
& After 2 min & & $39.67 \pm 2.9 *$ & $38.67 \pm 2.29 *$ & $36.86 \pm 0.89 * *$ \\
& After 5 min & & $41.67 \pm 2.9 * *$ & $38.67 \pm 1.33 *$ & $35.67 \pm 1.49 * *$ \\
& After 10 min & $45.83 \pm 1.83$ & $40.00 \pm 1.55 *$ & $40.00 \pm 0.52 * *$ \\
\hline
\end{tabular}

* means that value is significantly different from baseline values at $\mathrm{p}<0.05$.

**means that value is significantly different from baseline values at $\mathrm{p}<0.01$

$\mathrm{X}-1$ means the first intravenous injected dose of xylazine $(0.5 \mathrm{mg} \mathrm{kg}-1)$

$\mathrm{X}-2$ means the second same dose of xylazine after 10 min of first injection

$\mathrm{X}-3$ means the third same dose of xyazine after $10 \mathrm{~min}$ of second injection

Table 3: Mean $\pm \mathrm{SD}$ of duration (sec/mm) of electrocardiographic parameters in experimental donkeys before injection (Baseline) and after the three injections of xylazine.

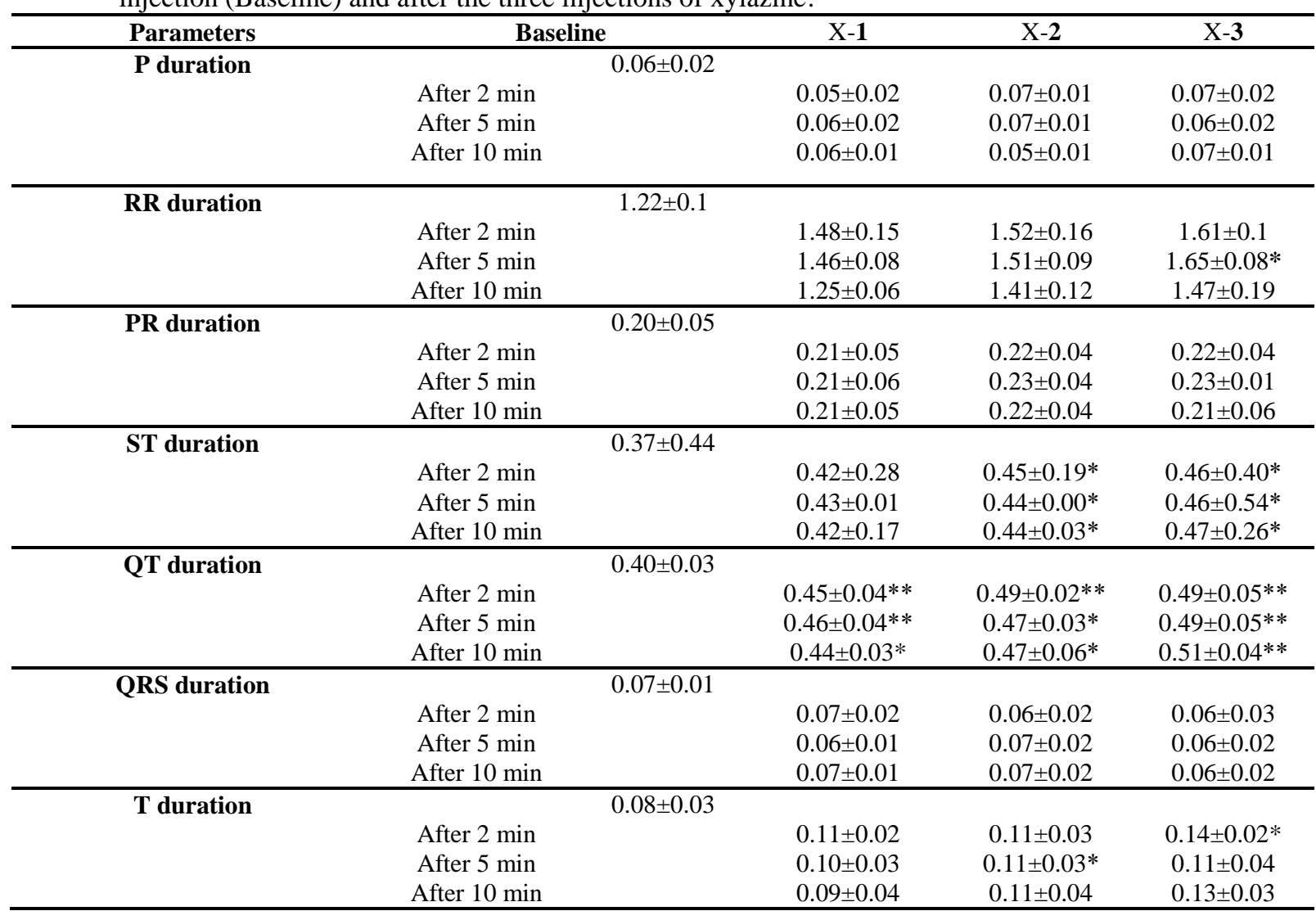

*means that value is significantly different from baseline values at $p<0.05$.

$* *$ means that value is significantly different from baseline values at $\mathrm{p}<0.01$

$\mathrm{X}-1$ means the first intravenous injected dose of xylazine $(0.5 \mathrm{mg} \mathrm{kg}-1)$

X-2 means the second same dose of xylazine after 10 min of first injection

X-3 means the third same dose of xyazine after $10 \mathrm{~min}$ of second injection 
Table 4: Mean \pm SD of amplitude $(\mathrm{mv} / \mathrm{mm})$ of electrocardiographic parameters in experimental donkeys before injection (Baseline) and after the three injections of xylazine.

\begin{tabular}{|c|c|c|c|c|}
\hline Parameters & Baseline & $X-1$ & $X-2$ & $X-3$ \\
\hline \multirow[t]{4}{*}{$P$ amplitude } & & & & \\
\hline & After $2 \mathrm{~min}$ & $0.28 \pm 0.05$ & $0.25 \pm 0.06$ & $0.25 \pm 0.10$ \\
\hline & After $5 \mathrm{~min}$ & $0.30 \pm 0.14$ & $0.28 \pm 0.09$ & $0.24 \pm 0.11$ \\
\hline & After $10 \mathrm{~min}$ & $0.25 \pm 0.13$ & $0.23 \pm 0.05$ & $0.21 \pm 0.06$ \\
\hline \multirow[t]{4}{*}{$R$ amplitude } & & & & \\
\hline & After 2 min & $1.53 \pm 0.37$ & $1.15 \pm 0.47$ & $1.30 \pm 0.34 * *$ \\
\hline & After 5 min & $1.25 \pm 0.30$ & $1.53 \pm 0.22 *$ & $1.15 \pm 0.47$ \\
\hline & After $10 \mathrm{~min}$ & $1.15 \pm 0.47$ & $1.35 \pm 0.25$ & $1.38 \pm 0.19^{*}$ \\
\hline \multirow[t]{4}{*}{ T amplitude } & & & & \\
\hline & After 2 min & $0.98 \pm 0.33$ & $0.93 \pm 0.39$ & $1.15 \pm 0.43^{*}$ \\
\hline & After 5 min & $0.53 \pm 0.15$ & $0.75 \pm 0.19$ & $0.75 \pm 0.54$ \\
\hline & After $10 \mathrm{~min}$ & $0.50 \pm 0.26$ & $0.63 \pm 0.35$ & $0.90 \pm 0.23$ \\
\hline \multirow[t]{4}{*}{ Q amplitude } & & & & \\
\hline & After 2 min & $0.04 \pm 0.05$ & $0.05 \pm 0.04$ & $0.06 \pm 0.04$ \\
\hline & After 5 min & $0.06 \pm 0.09$ & $0.05 \pm 0.04$ & $0.03 \pm 0.04$ \\
\hline & After $10 \mathrm{~min}$ & $0.05 \pm 0.04$ & $0.03 \pm 0.05$ & $0.03 \pm 0.03$ \\
\hline \multirow[t]{4}{*}{ S amplitude } & & & & \\
\hline & After 2 min & $0.09 \pm 0.06$ & $0.06 \pm 0.03$ & $0.03 \pm 0.05$ \\
\hline & After 5 min & $0.06 \pm 0.05$ & $0.03 \pm 0.05$ & $0.20 \pm 0.23$ \\
\hline & After $10 \mathrm{~min}$ & $0.00 \pm 0.00$ & $0.05 \pm 0.06$ & $0.05 \pm 0.06$ \\
\hline \multirow[t]{4}{*}{$P$ amplitude } & & & & \\
\hline & After $2 \mathrm{~min}$ & $0.28 \pm 0.05$ & $0.25 \pm 0.06$ & $0.25 \pm 0.10$ \\
\hline & After 5 min & $0.30 \pm 0.14$ & $0.28 \pm 0.09$ & $0.24 \pm 0.11$ \\
\hline & After $10 \mathrm{~min}$ & $0.25 \pm 0.13$ & $0.23 \pm 0.05$ & $0.21 \pm 0.06$ \\
\hline \multirow[t]{4}{*}{$\mathbf{R}$ amplitude } & & & & \\
\hline & After 2 min & $1.53 \pm 0.37$ & $1.15 \pm 0.47$ & $1.30 \pm 0.34 * *$ \\
\hline & After 5 min & $1.25 \pm 0.30$ & $1.53 \pm 0.22 *$ & $1.15 \pm 0.47$ \\
\hline & After $10 \mathrm{~min}$ & $1.15 \pm 0.47$ & $1.35 \pm 0.25$ & $1.38 \pm 0.19 *$ \\
\hline
\end{tabular}

* means that value is significantly different from baseline values at $\mathrm{p}<0.05$.

$* *$ means that value is significantly different from baseline values at $\mathrm{p}<0.01$

$\mathrm{X}-1$ means the first intravenous injected dose of xylazine $(0.5 \mathrm{mg} \mathrm{kg}-1)$

$\mathrm{X}-2$ means the second same dose of xylazine after $10 \mathrm{~min}$ of first injection

X-3 means the third same dose of xyazine after $10 \mathrm{~min}$ of second injection

\section{DISCUSSION}

In donkey practice, proper sedation and analgesia are often required to perform different standing surgical procedures (Matthews and van Loon, 2013). Alpha2adrenergic agonists (e.g. xylazine, detomidine, medetomidine, and romifidine) are widely used in equine practice for their sedative and analgesic effects (Valverde, 2010). A few studies have assessed the sedative effects of xylazine (Varshney et al., 1996) in donkeys, and sedation seems to be dosedependent. However, larger doses may be needed in donkeys to achieve similar degrees of sedation to those achieved in horses (Joubert et al., 1999). Aziz et al. (2008) describe laparoscopic ovariectomy with an average of 12 min duration in standing donkeys using xylazine sedation $(1 \mathrm{mg} / \mathrm{kg})$ and local infiltration of the laparoscopic portal sides with lidocaine. At recommended doses for donkeys (Lizarraga and Beths, 2012), xylazine usually induced short duration of sedation and analgesia. Previous reports stated that constant rate infusion protocols for xylazine and repeated doses of IV xylazine can be administrated to increase both sedation and analgesia in standing horse even for minor surgical procedures (Ringer et al., 2012). Similarly, our results demonstrated that deep sedation and analgesia with prolonged duration of sedation (71 \pm 6 minutes) and analgesia (62 \pm 5 minutes) was obtained after three repated doses of xylazine in donkeys.

All alpha2-adrenergic agonists have a dose-dependent effect on cardiovascular function (Yamashita et al., 
2000). In the present study, the decrease in HR was significant after every single injection. This could be attributed to a cumulative effect of xylazine on HR which could be also the cause of delaying the time of recovery until returning to the normal HR. The decrease in HR after xylazine injection can be attributed to one or more of the following mechanisms: inhibition of sympathetic tone, prevention of norepinephrine release from adrenergic endings, activation of vagus nerve in response to primary blood vessel contractions and increase in acetylcholine release from cardiac parasympathetic nerves (Ilback and Stalhandske, 2003).

There was no significance difference in P-wave and QRS intervals after repeated administration of xylazine indicating that xylazine at these doses had no effect on the atrial and ventricular depolarization time and area (Sarchahi et al., 2009). However, RRinterval was significantly increased after the third injection associated with absence of identified Pwaves (paroxysmal atrial fibrillation) that resulted from vagal stimulation (Chen and Tan, 2007). During atrial fibrillation, more excitation waves reach AV node at certain time resulting in concealment of conduction thus AV block is more common to occur in horses after vagal stimulation (Meijler et al., 1984).

For evaluating the effect of drug on AV conduction, it would be better to compare the changes in the PRinterval with controls or pre-dose values (Hanton and Rabemampianina, 2006). In the present study, PRinterval increased significantly 5 minutes after the second and third injections in comparison to base line value, which represented the first and the second degree of AV block (Morton et al., 2011).

Moreover, ST- interval increased significantly after the second and the third injections, this could be attributed to the inversed relation between ST duration and HR (Milhorn, 2005). Besides QTintervals increased significantly after xylazine administration, especially 10 minutes after the third injection. This could attribute to several causes; the inversed relation between QT- interval and heart rate, slow repolarization of ventricles, and decrease in the oxygen requirement of the heart as a result of xylazine administration (Dinu et al., 2007). R amplitude decreased after xylazine administration that denoted a marked reduction of myocardial concentration especially after second and the third injections.

On the basis of the obtained results, we can affirm that the changes in ECG parameters in this study could be attributed to increased vagal activity caused by the vasopressor effect of alpha- 2 agonist leading to decrease of HR and cardiac output (Knight, 1980). These effects had also been previously reported in horses (Dyson et al., 1998). In this study, the repeated administration of clinical recommended dosage of xylazine within short intervals amplifies some side effects of xylazine such as bradycardia after the first injection, and causes atrial fibrillation and AV block after the second injection. Typically, these arrhythmias are transient and not life threatening and are attributed to a baroreceptor mediated reflex to the peripheral vasoconstriction and diminished sympathetic outflow (Sinclair, 2003).

Further studies need to be conducted to evaluate the effects of co-administration of atropine with repeated xylazine administration on ECG in donkeys to counteract the transient cardiac effect of xylazine.

\section{CONCLUSION}

This study suggested that the dosages of xylazine $\mathrm{HCl}$ with 10 minutes intervals increased its sedative and analgesic period with transient cardiovascular effects in donkeys which make it a useful and safe method to ot obtain adequate sedation and analgesia to perform some surgical proceedures in standing postion in donkeys.

\section{REFERENCES}

Aziz, D.M.; Al-Badrany, M.S.; Taha, M.B. Laparoscopic ovariectomy in standing donkeys by using a new instrument. Animal Reproduction Science 107, 107-114.

Chen, P.S. and Tan, A.Y. (2007): Autonomic nerve activity and atrial fibrillation. Heart Rhythm; 4, 61-64.

Daunt, D.A. and Steffey, E.P. (2002): Alpha-2 adrenergic agonists as analgesics in horses. Vet. Clin. North Am. Equine Prac; 18, 39-46.

Dinu, C.; Nojana, N. and Mitrănescu, E. (2007): Electrocardiographic and haematological parameters and heart beat frequency in Arabian thoroughbred horses according to their adaptability to effort', Lucrari Stiintifice Universitatea de Stiinte Agricole a Banatului Timisoara, Med Vet-Recife; 40: 363-367.

Dyson, D.H.; Maxie, M.G. and Schnurr, D. (1998): Morbidity and mortality associated with anesthetic management in small animal veterinary practice in Ontario. J. Am Anim. Hosp. Assoc; 34, 325-335.

Fregin, G.F. (1985): Electrocardiography. Vet Clin. N. Am. Equine; 1, 419-432.

Hanton, G. and Rabemampianina, Y. (2006): The electrocardiogram of the Beagle dog: reference values and effect of sex, genetic strain, body position and heart rate. Lab Anim; 40, 123-136.

Hewes, C.A.; Keoughan, G.C. and Gutierrez-Nibeyro, S. (2007): Standing enucleation in the horse: a report of 5 cases. Canadian Vet J; 48, 512514. 
Hikasa, Y.; Ogasawara, S. and Takase, K. (1992): Alpha adrenoceptor subtypes involved in the emetic action in dogs. J. Pharmacol. Exp. Ther., 261, 746-754.

Ilback, N.G. and Stalhandske, T. (2003): Cardiovascular effects of xylazine recorded with telemetry in the dog. J. Vet. Med. A; 50, 479-483.

Joubert, K.E.; Briggs, P. and Gerber, D. (1999): The sedative and analgesic effects of detomidinebutorphanol and detomidine alone in donkeys. J. S. Afr. Vet. Assoc; 70, 112-118.

Kirkpatrick, R.M. (1978): Use of xylazine and ketamine as a combination anesthetic. Canine Pract., 5, 32-57.

Klide, A.M.; Calderwood, H.W. and Soma, R.L. (1975): Cardiopulmonary effect of xylazine in dogs. Am. J. Vet. Res. 36, 931-935.

Kolata, R.J. and Rawlings, C.A. (1982): Cardiopulmonary effects of intravenous xylazine, ketamine, and atropine in the dog. Am. J. Vet. Res., 43, 2196-2198.

Knight, A.P. (1980): Xylazine. JAVMA,; 176, 454455.

Lizarraga, I. and Beths, T. (2012): A comparative study of xylazine-induced mechanical hypoalgesia in donkeys and horses. Veterinary Anaesthesia and Analgesia 39, 533-538.

Matthews, N. and van Loon, J.P.A.M. (2013): Anaesthesia and analgesia of the donkey and the mule. Equine Veterinary Education 25, 47-51.

Meijler, F.L.; Kroneman, J. and van der Tweel, I. (1984): Nonrandom ventricular rhythm in horses with atrial fibrillation and its significance for patients. J. Am. Coll. Cardio; 4, 316-323.

Morton, A.J.; Varney, C.R. and Ekiri, A.B. (2011): Cardiovascular effects of Nbutylscopolammonium bromide and xylazine in horses. Equine Vet. J; 43, 117-122.

Milhorn, H.T. (2005): The electrocardiogram. In " Electrocardiography for the Family Physician: The Essentials" (H.T. Milhorn, Ed.), (11). Brown Walker Press.
Muir, W.W.; Werner, L.L. and Hamlin, R.L. (1975): Effects of xylazine and acetylpromazine upon induced ventricular fibrillation in dogs anesthetized with thiamylal and halothane. Am. J. Vet. Res., 36, 1299-1303.

Ringer, S.K.; Portier, K.G.; Fourel, I. and BettschartWolfensberger, R. (2012): Development of a xylazine constant rate infusion with or without butorphanol for standing sedation of horses. Veterinary Anaesthesia and Analgesia 39, $1-11$.

Sarchahi, A.A.; Vesal, N. and Nikahval, B. (2009): Comparison of the effects of different doses of acepromazine-xylazine on the electrocardiogram in dogs. Iran J. Vet. Re; 10, 208-215.

Sinclair, M.D. (2003): A review of the physiological effects of alpha2-agonists related to the clinical use of medetomidine in small animal practice. Canadian Vet. J; 44, 885-897.

Taylor, P.M.; Browning, A.P. and Harris, C.P. (1988): Detomidine-butorphanol sedation in equine clinical practice. Veterinary Record 123: 388-390.

Thurmon, J.C.; Tranquilli, W.J. and Benson, G.J. (1996): Lumb and Jones Veterinary Anesthesia, 3rd ed. altimore, Williams \& Wilkins, 185-186.

Valverde, A. (2010): Alpha-2 agonists as pain therapy in hoses. Vet. Clin. North Am Equine Pract 26, 515-532.

Varshney, JP.; Uppal, PK. and Yadav, MP. (1996): Evaluation of xylazine hydrochloride as sedative in donkeys. Indian Vet. J. 73, 24-27.

Yamashita, K.; Tsubakishita, S. and Futaok, S. (2000): Cardiovascular effects of medetomidine, detomidine and xylazine in horses. J. Vet. Med. Sci. 62, 1025-1032.

Young, L. (2004): Diseases of the heart and vessels. In: Hinchcliff, K.W., Kaneps, A.J., Geor, R.J. (editors). Equine Sports Medicine and Surgery - Basic and Clinical Sciences of the Equine Athlete. Elsevier Limited, Edinburgh, 728767.

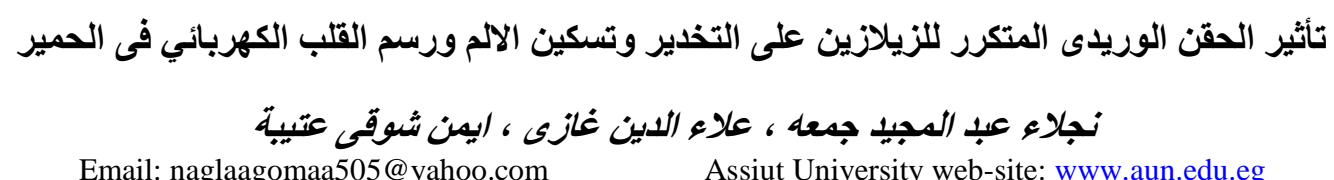

Email: naglaagomaa505@yahoo.com

Assiut University web-site: www.aun.edu.eg

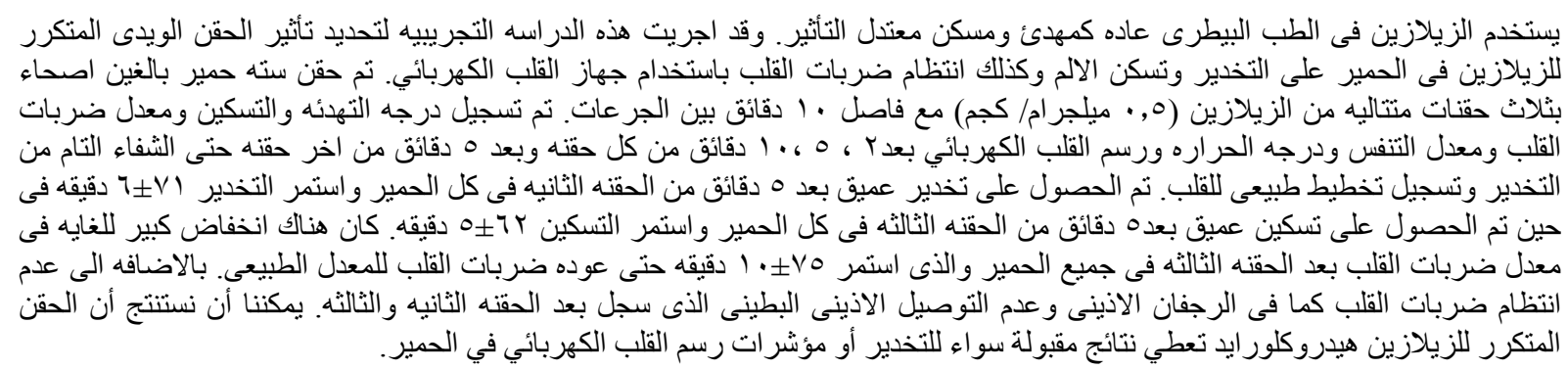

